\section{Chinese checkers}

\section{China sets a strong example on how to address scientific fraud.}

$\mathrm{T}$ he Chinese government knows that a slice of its generous science budget - the world's second-largest by country - goes to waste on bad science. It doesn't want to waste any more. On 30 May, the State Council and the Communist Party of China announced a radical new system of regulations to police science and raise research standards in the country.

Certainly, reform is necessary and overdue. Various Chinese government bodies have made the case to crack down on fraud and misconduct in science over the past two decades, but with limited success. This time, the changes have serious political weight behind them and could make a significant difference. The policy might offer the greatest disincentive to cheating in research that the world has seen so far. But the devil, as always, will be in the detail - and in how well the plans are enforced.

One of the most striking conditions is that researchers will be deterred from publishing findings in journals that China deems to be of poor academic quality, poorly managed and set up merely for profit. Many such 'predatory journals' offer researchers a place to publish, for a fee, and shirk their editorial responsibility to evaluate papers to determine quality. China's science ministry is working on a blacklist of those journals. In an unprecedented step, any researcher who publishes in one will get a warning and be given no credit for the publication when they are evaluated for grants or jobs. Using government grants to pay the publication fees in these journals, as many presumably do, could land Chinese scientists in deeper trouble.

As the world's largest producer of scientific papers, China's new rules could go as far as to put some of these rogue journals out of business, and that could be good for scientists everywhere. (Although, as we discuss in a News story this week on page 171, some scientists are anxious about how these journals are identified, while others have concerns about such blacklists and prefer 'whitelists' of approved publications.)

In another major shift, China is handing the responsibility for deterring and investigating scientific misconduct to the government's science ministry. That's quite a shake-up for China, where - as in many places - institutions are usually expected to investigate allegations against their own researchers. That is too often ineffective. With little to gain and a reputation to lose, many prefer to sit on their hands
"Thepolicy might offer the greatest disincentive to cheating in research that the world has seen." and wait for the situation to blow over.

Denmark, for instance, has designated a national agency to police science, but, too frequently, there is limited will and scant resources to pursue allegations of fraud at the government level. In the United States, for example, the Office of Research Integrity is short-staffed and has limited leverage over universities.

In China, the situation could play out differently. The new rules state explicitly that institutions that shield errant scientists can be punished through a loss of funding. That could give the policy real teeth - enough to drastically clean up Chinese research. But success will take sustained effort and pressure from the top, and because there is no guarantee of that, the policy could equally fall flat. China's bureaucrats are not responsive to its citizens - no matter how loud the cry on social media for an investigation into a given scientist - and they make almost no effort to be transparent. The science ministry could stick its head in the sand just as deeply as some institutions do.

There are other causes for concern. The science ministry is also drawing up rules on how penalties will be meted out - including the blacklisting of scientists who have committed particularly egregious acts. To maintain fairness, harsh penalties require assurances that the judgements leading to them are based on thorough and fair evaluations.

China's bureaucrats might not answer to the people, but they do answer to the higher echelons of power. The current push for better management of science comes as part of President Xi Jinping's wider anti-corruption drive. Xi regularly talks up the crucial role of science and technology in making China stronger and more independent. With its new rules, China is backing words with actions.

\section{Not necessary}

\section{Phrase 'necessary and sufficient' blamed for flawed neuroscience.}

$\mathrm{I}$ n his 1946 classic essay 'Politics and the English language', George Orwell argued that "if thought corrupts language, language can also corrupt thought". Can the same be said for science - that the misuse and misapplication of language could corrupt research? Two neuroscientists believe that it can. In an intriguing paper published in the Journal of Neurogenetics, the duo claims that muddled phrasing in biology leads to muddled thought and, worse, flawed conclusions (M. Yoshihara and M. Yoshihara J. Neurogenet. 32, 53-64; 2018).

The phrase in the crosshairs is "necessary and sufficient". It's a popular one: figures suggest the wording pops up in some 3,500 scientific papers each year across genetics, cell biology and neuroscience alone. It's not a new fad: Nature's archives show consistent use since the nineteenth century.

Used properly, the phrase indicates a specific relationship between two events. For example, the statement, "I'll pay for lunch if, and only if, you pay for breakfast," can be written as, "You paying for breakfast is necessary and sufficient for me paying for lunch."

But, argue Motojiro Yoshihara and Motoyuki Yoshihara, use of the phrase in research reports is problematic, and should be curtailed.

The logic of the term is at the heart of the dispute. It's too often used as shorthand to mean 'linked to' or 'important for', the authors say. And this sloppy use, they argue, can lead scientists in the wrong direction, especially in genetics.

If a gene is necessary and sufficient for something (as often claimed), strict logic demands that that gene alone can do the job. For example, the gene eyeless is certainly necessary for a retina to develop. But it is not sufficient - if it were, then logic would demand that 'if eyeless exists, then a retina will develop'. This is false; other genes and factors are needed as well. Yet eyeless is often described as being necessary and sufficient for retinal development.

The duo argues that its objection to such incorrect use is more than pedantry. The combination of necessary and sufficient is excessively strict, and its widespread use has meant, for example, that some 'command' neurons have failed to be identified as such because they don't satisfy the required criteria. (The agreed definition of a command neuron is one that is necessary and sufficient to initiate a behaviour.)

One such missed neuron is the Mauthner cell, responsible for a fast-escape reflex in fishes and amphibians. In fact, so few command neurons satisfy the logic of the phrase that the concept that they exist at all has been undermined, the authors say.

In most cases, they propose, a better phrase than 'necessary and sufficient' would be "indispensable and inducing". (Number of uses so far: one, in their paper.)

Will it catch on? Biologists will no doubt counter that they use the 'necessary and sufficient' phrase in a mutually understood way that is separate from its logical roots. Perhaps, but then Orwell had that covered, too: "A bad usage can spread by tradition and imitation even among people who should and do know better." - 